\title{
Article \\ Effect of a Defective Clamp Loader Complex of DNA Polymerase III on Growth and SOS Response in Pseudomonas aeruginosa
}

\author{
Maria Concetta Spinnato ${ }^{1}$, Alessandra Lo Sciuto ${ }^{1}$, Jessica Mercolino ${ }^{1}$, Massimiliano Lucidi ${ }^{1}$, Livia Leoni ${ }^{1}{ }^{\mathbb{D}}$, \\ Giordano Rampioni ${ }^{1,2}$, Paolo Visca ${ }^{1,2}$ and Francesco Imperi ${ }^{1,2, *(D)}$ \\ 1 Department of Science, Roma Tre University, 00146 Rome, Italy; mariaconcetta.spinnato@uniroma3.it (M.C.S.); \\ alessandra.losciuto@uniroma3.it (A.L.S.); jes.mercolino@stud.uniroma3.it (J.M.); \\ massimiliano.lucidi@uniroma3.it (M.L.); livia.leoni@uniroma3.it (L.L.); \\ giordano.rampioni@uniroma3.it (G.R.); paolo.visca@uniroma3.it (P.V.) \\ 2 IRCCS Fondazione Santa Lucia, 00179 Rome, Italy \\ * Correspondence: francesco.imperi@uniroma3.it
}

Citation: Spinnato, M.C.; Lo Sciuto, A.; Mercolino, J.; Lucidi, M.; Leoni, L.; Rampioni, G.; Visca, P.; Imperi, F. Effect of a Defective Clamp Loader Complex of DNA Polymerase III on Growth and SOS Response in Pseudomonas aeruginosa.

Microorganisms 2022, 10, 423.

https://doi.org/10.3390/

microorganisms10020423

Academic Editors: Vincenzo Scarlato and Davide Roncarati

Received: 23 January 2022

Accepted: 10 February 2022

Published: 12 February 2022

Publisher's Note: MDPI stays neutral with regard to jurisdictional claims in published maps and institutional affiliations.

Copyright: (c) 2022 by the authors. Licensee MDPI, Basel, Switzerland. This article is an open access article distributed under the terms and conditions of the Creative Commons Attribution (CC BY) license (https:// creativecommons.org/licenses/by/ $4.0 /)$.

\begin{abstract}
DNA polymerase III (Pol III) is the replicative enzyme in bacteria. It consists of three subcomplexes, the catalytic core, the $\beta$ clamp, and the clamp loader. While this complex has been thoroughly characterized in the model organism Escherichia coli, much less is known about its functioning and/or its specific properties in other bacteria. Biochemical studies highlighted specific features in the clamp loader subunit $\psi$ of Pseudomonas aeruginosa as compared to its E. coli counterpart, and transposon mutagenesis projects identified the $\psi$-encoding gene holD among the strictly essential core genes of $P$. aeruginosa. By generating a $P$. aeruginosa holD conditional mutant, here we demonstrate that, as previously observed for E. coli holD mutants, HolD-depleted P. aeruginosa cells show strongly decreased growth, induction of the SOS response, and emergence of suppressor mutants at high frequency. However, differently from what was observed in E. coli, the growth of P. aeruginosa cells lacking HolD cannot be rescued by the deletion of genes for specialized DNA polymerases. We also observed that the residual growth of HolD-depleted cells is strictly dependent on homologous recombination functions, suggesting that recombination-mediated rescue of stalled replication forks is crucial to support replication by a $\psi$-deficient Pol III enzyme in P. aeruginosa.
\end{abstract}

Keywords: essential gene; conditional mutagenesis; homologous recombination; replication; replication fork stalling; RuvABC; SOS response; specialized DNA polymerases

\section{Introduction}

Genome replication is crucial for the transmission of genetic instructions that drive life processes in all organisms. Bacteria can replicate DNA at very high speed and with remarkable fidelity, through the activity of a complex protein machinery named replisome [1-3]. This machinery consists of a helicase (DnaB), a primase (DnaG), single-stranded DNA binding protein (SSB), and the DNA Polymerase III (Pol III) holoenzyme, also known as replicase, which is the main replicative DNA polymerase in bacterial cells. The Pol III enzyme is endowed with important properties that are required for efficient DNA replication, including a rapid elongation rate, high processivity, and tolerance to physiological salt concentrations [4,5].

Pol III can be divided into three subcomplexes, namely the catalytic core, the $\beta$ clamp, and the clamp loader [4,5] (Figure 1). Extensive genetic and biochemical studies, most of which performed in Escherichia coli as model organism or using the E. coli replicase in vitro, have elucidated the architecture and function of the three subcomplexes and the importance of their different subunits. The Pol III core is composed of the subunits $\alpha$ (the polymerase catalytic subunit), $\varepsilon$ (the proofreading $3^{\prime}-5^{\prime}$ exonuclease), and $\theta$, a nonessential subunit that appears to be specific to Enterobacteriaceae [4-6]. The ring-shaped $\beta$ clamp (or sliding clamp), formed by a dimer of the $\beta$ subunit, encircles the double-stranded DNA 
(dsDNA), slides along dsDNA, and tethers the Pol III core to the DNA, hence significantly increasing the processivity of DNA replication $[7,8]$. The clamp loader (also known as the DnaX complex) is responsible for loading the sliding clamp onto DNA. In E. coli it consists of three monomers of the $\gamma$ and / or $\tau$ subunits (both encoded by the $d n a X$ gene through a programmed translational frameshift) and one monomer each of the $\delta, \delta^{\prime}, \chi$ and $\psi$ subunits, although the complex $\tau / \gamma_{3} \delta \delta^{\prime}$ appears to be the minimal module sufficient for $\beta$ clamp loading [8]. The Pol III holoenzyme contains two copies of the Pol III core, each responsible for replication of one DNA strand, which are connected by the attachment to a single clamp loader [9] (Figure 1). The accessory clamp loader subunits $\chi$ and $\psi$ form a tight 1:1 complex involved in tethering the clamp loader to the SSBs, which coat single-stranded DNA (ssDNA) at the lagging strand to protect it from degradation, thus increasing the efficiency of lagging strand synthesis. Moreover, the $\chi \psi$ complex contributes to stabilizing the clamp loader and increasing its affinity for the $\beta$ clamp [8].

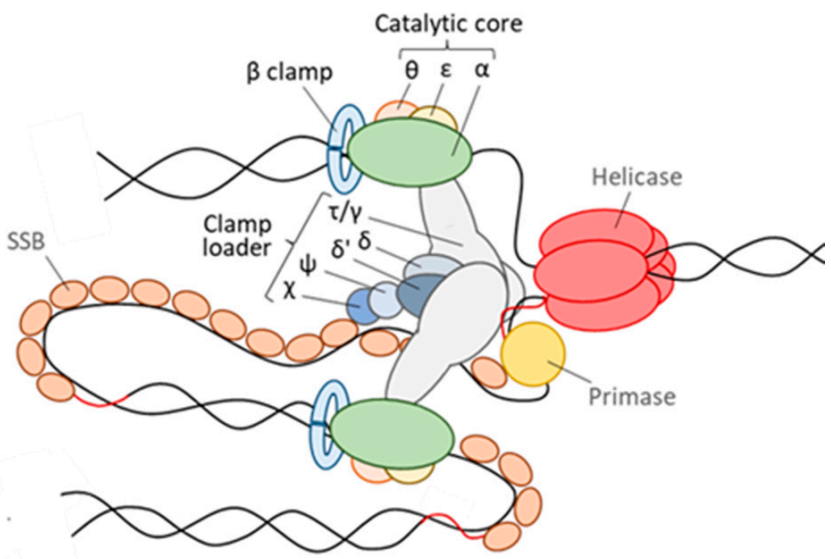

Figure 1. Schematic of the prototypical Pol III holoenzyme. The three subcomplexes of the Pol III holoenzyme, namely the catalytic core, the $\beta$ clamp and the clamp loader, and their protein subunits are shown in the figure. The bacterial replisome also includes a helicase, which unwinds the doublestranded DNA (dsDNA), a primase, which synthesizes the short RNA primers (in red), and SSB proteins, which bind to and protect single-stranded DNA (ssDNA) filaments.

The protein subunits of the replisome are overall highly conserved among bacterial phyla $[10,11]$. However, relatively few studies have investigated how they work in bacteria other than E. coli or whether they are endowed with different functions with respect to their E. coli homologs. For instance, work aimed at characterizing the in vitro biochemical properties of the replisome machinery of the human pathogen Pseudomonas aeruginosa revealed that this bacterium has a highly divergent $\psi$ subunit that cannot be identified by homology search and that is almost twice as large as the E. coli $\psi$ subunit $[12,13]$. At the functional level, the P. aeruginosa $\chi \psi$ complex appears to play a more significant role than its E. coli counterpart, as in vitro it is required for efficient clamp loader activity under physiological salt concentrations and can directly bind to ssDNA via an additional $N$-terminal domain of $\psi$, both properties being absent from the $E$. coli $\chi \psi$ complex $[13,14]$.

In agreement with the accessory role of $\psi$ in clamp loader activity in vitro, the $\psi$ encoding gene holD was deemed as a nonessential gene in E. coli [15-17], even if a recent transposon mutagenesis project argued against this notion [18]. E. coli holD deletion mutants have been obtained and are characterized by frequent replication fork arrests, hyperactivation of the SOS response, appearance of suppressor mutants at high frequency, and severe growth defects, that are mainly caused by the overexpression of SOS-induced specialized DNA polymerases $[16,17,19]$.

Several independent transposon mutagenesis studies aimed at determining the "essentialome" (i.e., the complete set of genes that are individually essential in a given organism) of $P$. aeruginosa identified holD among the genes that were never disrupted by transposon 
insertions in different P. aeruginosa strains and under several culture conditions [20-25], strongly suggesting that the HolD protein plays a crucial role in P. aeruginosa physiology. Notably, P. aeruginosa insertion mutants in the holC gene, which encodes the $\chi$ subunit of the clamp loader, were instead obtained in most studies and/or conditions [20-25].

To confirm the essentiality of holD and to investigate the effect of HolD depletion in P. aeruginosa, in this study we report the generation of a holD conditional mutant and demonstrate that, as previously observed for E. coli holD mutants [16,17,19], HolD-depleted P. aeruginosa cells are characterized by a strongly decreased growth, constitutive induction of the SOS response and frequent emergence of suppressor mutants. However, different from what was observed in E. coli [17], the growth of P. aeruginosa cells lacking HolD cannot be restored by the inactivation of specialized DNA polymerases. Moreover, we observed that a functional homologous recombination pathway is essential for residual growth of HolD-depleted P. aeruginosa cells, suggesting that the reactivation of stalled replication forks through recombination plays a pivotal role during replication by a $\psi$-deficient Pol III enzyme in P. aeruginosa.

\section{Materials and Methods}

\subsection{Bacterial Strains and Growth Media}

Bacterial strains used in this study are listed in Table S1. Bacteria were cultured in Lysogeny Broth, Lennox formulation (LB; Acumedia, Neogen, Milan, Italy) for genetic manipulation, while growth assays were performed in Mueller-Hinton broth (MH; Difco, Becton Dickinson, Milan, Italy). When specified, growth media were supplemented with rhamnose or IPTG at the indicated concentrations. When required, antibiotics were added at the following concentration for E. coli (the concentration used for P. aeruginosa are shown between brackets): ampicillin $100 \mu \mathrm{g} / \mathrm{mL}$, nalidixic acid $20 \mu \mathrm{g} / \mathrm{mL}$, chloramphenicol $30 \mu \mathrm{g} / \mathrm{mL}(350 \mu \mathrm{g} / \mathrm{mL})$, tetracycline $12 \mu \mathrm{g} / \mathrm{mL}(50-100 \mu \mathrm{g} / \mathrm{mL})$.

\subsection{Generation of Plasmids}

Recombinant DNA procedures have been described elsewhere [26]. All DNA fragments for cloning were amplified by PCR using the Q5 Hot Start High-Fidelity DNA Polymerase (New England Biolabs, Euroclone, Milan, Italy) and the genomic DNA of P. aeruginosa PAO1 as the template. Primers and restriction enzymes used for cloning are described in Table S2. All the constructs generated in this study were verified by restriction analysis and DNA sequencing and are described in Table S1.

The integration-proficient construct pJM253holD was generated by directionally cloning the coding sequence of the holD gene into the mini-CTX1 derivative pJM253 [27] downstream of the rhaRS-P rhaBAD regulatory element.

The deletion mutagenesis constructs $\mathrm{pDM} 4 \Delta$ holD, $\mathrm{pDM} 4 \Delta$ polA, $\mathrm{pDM} 4 \Delta \mathrm{polB}, \mathrm{pDM} 4 \Delta \operatorname{din} B$ and $\mathrm{pDM} 4 \Delta i m u \mathrm{C}$ were obtained by directionally cloning two DNA fragments of about $500 \mathrm{bp}$ each, corresponding to the upstream and downstream regions of the coding sequence of each gene of interest, into pBluescript II KS+ (Table S1), followed by DNA sequencing and subcloning of the entire insert encompassing the upstream and downstream regions of the gene of interest into the suicide vector pDM4 [28]. To obtain the construct for the deletion mutagenesis of ruv $C A B$ genes (pDM4 $\triangle r u v C A B$ ), two DNA fragments corresponding to the region upstream of ruv $C$ and the region downstream of ruv $B$ were directionally cloned into pBluescript II KS, checked by sequencing and then subcloned into $\mathrm{pDM} 4$. The construct $\mathrm{pDM} 4 \Delta r e c A$ has been described elsewhere [29].

To generate the construct for IPTG-inducible expression of FtsZ fused to GFP (pME $f t s Z-G F P$ ), the ftsZ coding sequence without the stop codon was amplified and cloned into pBluescript II KS. The GFP coding sequence was amplified from pPS858 [30] and cloned in frame downstream of the ftsZ coding sequence. Then, the resulting ftsZ-GFP fusion gene was verified by sequencing and subcloned into the shuttle vector pME6032 [31] downstream of the $\mathrm{P}_{\text {tac }}$ promoter. 
The expressing constructs pMEpolA, pMEpolB, pMEdinB and pMEimuBC (Table S1) were generated by cloning the PCR-amplified gene(s) of interest, without the endogenous promoter, into the IPTG-inducible shuttle vector pME6032 downstream of the $\mathrm{P}_{\text {tac }}$ promoter. The pME6032 derivatives were introduced into P. aeruginosa by transformation using chemically competent cells.

\subsection{Generation of Mutant Strains}

Deletion mutants were obtained by homologous recombination using the $s a c B$-based suicide pDM4 derivatives, as previously described [32].

To obtain the P. aeruginosa PAO1 holD conditional mutant, the holD coding sequence under the control of the rhamnose-dependent regulatory element in pJM253holD was integrated into the $a t t B$ neutral site of the P. aeruginosa PAO1 chromosome, and the miniCTX1 plasmid backbone was excised by Flp-mediated site-specific recombination as described [33]. Then, in-frame deletion of the endogenous copy of holD was obtained under permissive condition (i.e., growth in the presence of $0.01 \%$ rhamnose) using the $s a c B$-based suicide construct $\mathrm{pDM} 4 \Delta h \mathrm{hlD}$, as previously described [32].

\subsection{Growth Assays}

Growth assays in liquid cultures were performed in 96-well microtiter plates $(200 \mu \mathrm{L}$ of medium in each well) or in flasks at $37^{\circ} \mathrm{C}$ and vigorous shaking (200 rpm). Growth was measured as the optical density at $600 \mathrm{~nm}$ wavelength $\left(\mathrm{OD}_{600}\right)$ of bacterial cultures in a Tecan Spark 10M microtiter plate reader for microtiter plates or of appropriate dilutions in sterile growth medium in a spectrophotometer for flask cultures. To obtain HolD-depleted cells of the holD conditional mutant derivatives that did not grow in the absence of the inducer, a previously described dual-refresh culturing strategy was used [34]. Briefly, cells were cultured overnight in the presence of $0.01 \%$ rhamnose and then refreshed at high cell density (1:20 dilution) in the absence of rhamnose, or in the presence of $0.01 \%$ rhamnose as control, cultured for $2 \mathrm{~h}$ and then refreshed again (1:30 dilution) in the same medium. HolD-depleted cells were collected as soon as a growth defect was observed with respect to control cultures.

Growth assays on solid media were performed by directly streaking bacterial suspensions normalized in saline at an $\mathrm{OD}_{600}=1$, obtained from late-exponential cultures grown in the presence of $0.01 \%$ rhamnose, onto $\mathrm{MH}$ solidified with $1.5 \%$ agar with a $1-\mu \mathrm{L}$ inoculation loop. Plating efficiency was investigated by spotting $5 \mu \mathrm{L}$ of serial ten-fold dilutions from the same bacterial suspensions onto $\mathrm{MH}$ agar plates supplemented or not with rhamnose. The frequency of fast-growing colonies for the holD conditional mutant and its derivatives was determined by plating $50 \mu \mathrm{L}$ of the bacterial suspensions normalized at $\mathrm{OD}_{600}=1$ onto $\mathrm{MH}$ agar plates without rhamnose and by dividing the number of colonies obtained on these plates to the number of colony forming units (CFU) determined by plating ten-fold serial dilutions onto $\mathrm{MH}$ agar plates supplemented with $0.01 \%$ rhamnose.

\subsection{Gene Expression Analysis}

The expression level of selected SOS genes and of DNA polymerase genes was determined by quantitative reverse transcription PCR (qRT-PCR). Bacterial cells were harvested by centrifugation and treated with RNAprotect Bacteria Reagent (Qiagen, Milan, Italy). RNA was purified using the RNeasy Mini kit (Qiagen), treated with DNase, and re-purified with the RNeasy MinElute Cleanup kit (Qiagen). cDNA was reverse transcribed from 100 ng of RNA with Prime Script RT Reagent Kit (Takara, Unimed Scientifica, Rome, Italy). Appropriate dilutions of the cDNA were used as template for qRT-PCR in a AriaMx RealTime PCR System (Agilent Technologies, Rome, Italy) using TB Green Premier EX Taq master mix (Takara) and the primers listed in Table S2. Relative gene expression with respect to the housekeeping gene $r p o D$ was calculated using the $2^{-\Delta \Delta C t}$ method [35]. 


\subsection{Confocal Microscopy}

Cells carrying the constructs pMEftsZ-GFP were cultured in MH supplemented with $0.003 \mathrm{mM}$ IPTG in the absence or presence of $0.01 \%$ rhamnose, as described above. Cells were collected by centrifugation, washed and suspended in saline in the presence of the fluorescent dye FM4-64 (10 $\mu \mathrm{g} / \mathrm{mL})$ [36], and incubated at $37^{\circ} \mathrm{C}$ for $1 \mathrm{~h}$. Then, the excess of FM4-64 was removed by an additional wash in saline. Five $\mu \mathrm{L}$ of the bacterial cell suspensions were spotted on a microscope glass slide overlaid with $0.5 \%$ agarose and imaged with a NikonA1+ confocal laser scanning microscope equipped with an Apo TIRF $100 \times$ oil immersion objective (NA 1.49). The 488 and $561 \mathrm{~nm}$ laser lines were employed for the GFP and FM4-64 excitation, respectively. The emission bandwidths at 500-540 nm and $600-720 \mathrm{~nm}$ were used for the GFP and FM4-64 detection, respectively. The images were acquired at a sampling dimension of $512 \times 512$ pixels and were deconvoluted using the NIS-Elements software (Nikon, Amsterdam, The Netherlands), using default parameters.

\subsection{Statistical Analysis}

Statistical analysis was performed with the software GraphPad Instat, using one-way analysis of variance (ANOVA) followed by Tukey-Kramer multiple comparison test.

\section{Results}

\subsection{HolD Depletion Strongly Delays P. aeruginosa Growth}

To verify the essentiality of the $P$. aeruginosa holD orthologue, we first tried to generate a holD clean deletion mutant in the reference strain PAO1 (annotated as PA4679). However, despite the numerous attempts, we were unable to delete the holD gene from the P. aeruginosa PAO1 chromosome. We therefore generated an holD conditional mutant through a previously described strategy [27], based on the introduction of a copy of the $h o l D$ coding sequence under a rhamnose dependent promoter in a neutral site (attB) of the chromosome, followed by in-frame deletion of the endogenous holD gene under permissive conditions (presence of rhamnose in the growth medium). Notably, while the coding sequence of holD in PAO1 and other P. aeruginosa strains is annotated as a 702-bp sequence, encoding a 233-aa polypeptide (www.pseudomonas.com; accessed on 2 January 2021), Jarvis and co-workers have demonstrated that the $\psi$ subunit of the P. aeruginosa Pol III that is functional in vitro is 278-aa long, deriving from a translational start site located $135 \mathrm{nt}$ upstream of the annotated one for PA4679 [13] (Figure S1). In line with the finding of Jarvis et al., we failed to generate the conditional mutant by using a rhamnose-dependent PA4679 coding sequence corresponding to the 233-aa polypeptide (data not shown), while we readily obtained the holD conditional mutant when the longer coding sequence was introduced under the rhamnose-dependent promoter into the P. aeruginosa PAO1 chromosome. This evidence indirectly confirms that the 278-aa long protein is the functional P. aeruginosa HolD also in vivo.

The growth of the holD conditional mutant was confirmed to be strongly dependent on rhamnose, and a marked reduction of growth kinetics and yields with respect to the wildtype was observed when the mutant was cultured in the absence of rhamnose (Figure 2a), explaining the failure in generating holD knock-out mutants in P. aeruginosa during transposon mutagenesis and Tn-seq studies [20-25]. Notably, HolD-depleted cells showed some residual growth under non-inducing conditions, and this was confirmed by streaking the mutant on agar plates, where relevant growth was observed after prolonged incubation $(>30 \mathrm{~h}$ ) in the absence of rhamnose (Figure 2b). Growth assays on plates also suggested the presence of fast-growing colonies in the absence of rhamnose, here defined as colonies that were clearly visible within the first $24 \mathrm{~h}$ of growth, when the bulk of the population was unable to develop detectable colonies (Figure 2b). Spotting of serial dilutions of bacterial cultures grown in the presence of rhamnose onto agar plates supplemented or not with the inducer confirmed the emergence of such fast-growing cells under non-inducing conditions, with an apparent frequency of about $10^{-4}$ in the bacterial population (Figure 2c). The lack or depletion of Pol III subunits hampers or delays DNA replication, resulting in elongated 
or filamentous bacterial cells [37-39]. Moreover, since cell division is temporally and spatially dependent on chromosome replication, a defective replisome activity can result in inhibition or mislocalization of the divisome machinery $[37,40,41]$. To verify if these phenotypes were also associated with HolD depletion in P. aeruginosa, we generated and introduced into the wild-type and the holD conditional mutant a plasmid (pMEftsZ-GFP) for the IPTG-inducible expression of a fusion protein between the green fluorescent protein (GFP) and FtsZ, a pivotal divisome protein that, by polymerizing into the $\mathrm{Z}$ ring, defines the division site and recruits the downstream divisome proteins that drive cell constriction $[42,43]$. Preliminary experiments were performed to identify the optimal IPTG concentration that allows detectable expression of the FtsZ-GFP fusion protein without affecting bacterial growth and cell morphology (Figure S2). Wild type cells and holD conditional mutant cells were then cultured with the selected IPTG concentration $(0.003 \mathrm{mM})$ and subjected to confocal microscopy analysis. As shown in Figure 2d, wild-type cells, as well as conditional mutant cells cultured in the presence of rhamnose, showed a normal rod shape with the $\mathrm{Z}$ ring correctly localized at the mid cell, in line with the septum position in dividing cells. In contrast, conditional mutant cells grown under non-inducing conditions appeared elongated, without a definite mid-cell Z ring and with a more diffused FtsZ-GFP fluorescence inside the cell (Figure 2d), suggesting that HolD depletion leads to a delayed and/or defective chromosome replication that, in turn, hampers the proper assembly of the divisome machinery.

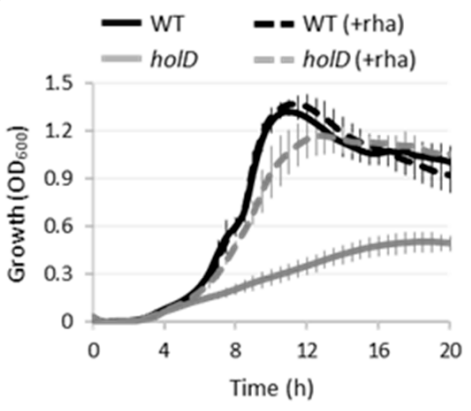

b

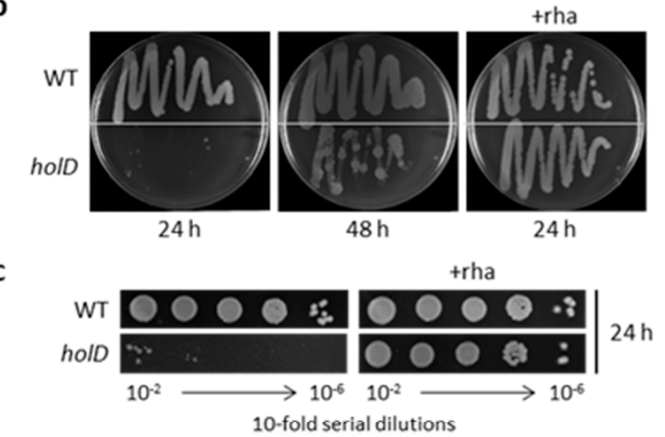

d

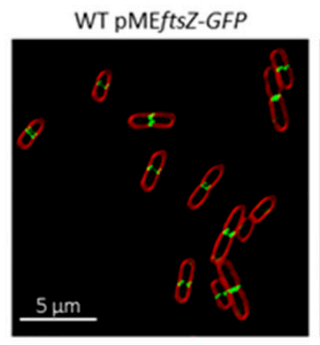

holD pMEftsZ-GFP
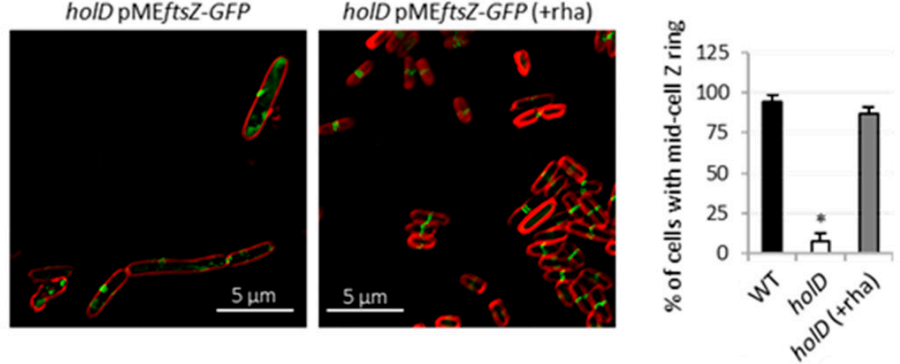

Figure 2. Effect of HolD depletion in P. aeruginosa. (a) Growth curves of the P. aeruginosa wild-type (WT) strain PAO1 and the holD conditional mutant (holD) at $37{ }^{\circ} \mathrm{C}$ in $\mathrm{MH}$ supplemented or not with $0.01 \%$ rhamnose (+rha). Data are the mean $( \pm \mathrm{SD})$ of three independent assays. (b) Growth and (c) plating efficiency of PAO1 and holD on MH agar plates supplemented or not with $0.01 \%$ rhamnose (+rha) after 24 and/or $48 \mathrm{~h}$ of incubation at $37^{\circ} \mathrm{C}$. (d) Confocal microscopy images of PAO1 and holD expressing the fusion protein FtsZ-GFP cultured in the presence of $0.003 \mathrm{mM}$ IPTG and, when indicated, $0.01 \%$ rhamnose (+rha), and stained with the membrane dye FM4-64. The graph on the right shows the percentage of cells showing mid-cell localization of the FtsZ-GFP fusion protein for PAO1, holD and holD cultured in the presence of rhamnose (+rha). Data are the mean $( \pm \mathrm{SD})$ of three independent experiments, and at least 50 cells were analyzed per sample and experiment. The asterisk indicates a statistically significant difference $(p<0.05)$ with respect to the WT strain. Images in panels $(\mathbf{b}-\mathbf{d})$ are representative of at least three independent experiments. 


\subsection{The SOS Response Is Induced in HolD-Depleted P. aeruginosa Cells}

Poor functioning or reduced activity of the Pol III can impede the replication fork progression, and this often results in an increased frequency of fork stalling and accumulation of ssDNA gaps $[16,44]$. The ssDNA is known to activate the RecA protein and induce the SOS response, a global stress response to DNA damages that induces low-fidelity DNA repair mechanisms and error-prone specialized DNA polymerases, generally leading to increased mutagenesis rates $[45,46]$. Accordingly, the SOS response was found to be constitutively induced in E. coli cells with a defective clamp loader complex of Pol III due to the lack of the $\psi$ subunit [17]. Given that the emergence of fast-growing variants among HolD-depleted P. aeruginosa cells is suggestive of suppressor mutants, which seems to occur with a relatively high frequency (Figure 2c), we wondered whether HolD depletion leads to the induction of the SOS response in P. aeruginosa as well. Therefore, the expression levels of well-known SOS genes $(\operatorname{recN}$, recX, lexA and imuB) [47-49] were compared by qRT-PCR between the wild-type and the holD conditional mutant cultured in the presence or in the absence of rhamnose. We observed an increase in the mRNA levels of the four SOS genes in HolD-depleted cells as compared to wild-type cells, although the increase was not statistically significant for $r e c X$ (Figure 3). As expected, the expression of these genes was overall restored to wild-type levels when the holD conditional mutant was cultured in the presence of rhamnose (Figure 3). This result confirms that a clamp loader complex deficient of HolD also induces the SOS response in P. aeruginosa.

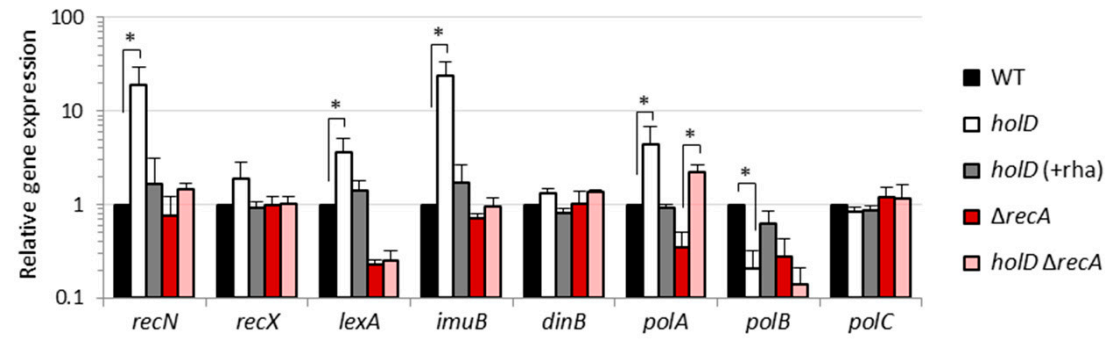

Figure 3. HolD depletion induces the SOS response and affects the expression of DNA polymerases. Expression levels of the SOS genes $\operatorname{rec} N$, $\operatorname{rec} X$, lex $A$, and $i m u B$ and of the DNA polymerase genes $\operatorname{din} B$, polA, polB, and polC, determined by qRT-PCR, in the P. aeruginosa wild-type (WT) strain PAO1, the holD conditional mutant (holD), the $\triangle r e c A$ mutant, and the holD $\triangle r e c A$ conditional mutant, cultured in the absence or in the presence of $0.01 \%$ rhamnose (+rha). Relative gene expression is shown as fold induction with respect to the W.T. Data represent the mean $( \pm S D)$ of three independent experiments performed in triplicate. The asterisks indicate a statistically significant difference $(p<0.05)$ in holD and holD $\triangle r e c A$ with respect to the cognate HolD-replete strains WT and $\Delta r e c A$, respectively.

\subsection{RecA Sustains the Residual Growth of HolD-Depleted, P. aeruginosa Cells}

The observed induction of SOS genes in P. aeruginosa cells depleted of HolD suggests that the SOS response could play a role in the residual growth of the holD conditional mutant and/or the emergence of fast-growing variants under non-inducing conditions (Figure 2), by triggering the expression of specialized DNA polymerases that can either partially sustain replication in Pol III defective cells or increase the mutation rates. To explore this hypothesis, we deleted the rec $A$ gene in the holD conditional mutant and in the wild-type as control, thus obtaining strains unable to induce the SOS response. The lack of RecA did not significantly affect the growth of the wild-type strain, while it almost abrogated the residual growth of HolD-depleted cells, both in liquid cultures and on agar plates (Figure $4 a, b$ ). The qRT-PCR analysis showed that the induction of SOS genes observed in HolD-depleted cells was nearly completely abolished upon deletion of recA (Figure 3), confirming that the SOS response is inactive in cells lacking RecA. It is interesting to note that, except for lexA, which is one of the most responsive SOS genes in P. aeruginosa [47,49], the expression of other $\mathrm{SOS}$ genes was not affected by rec $A$ inactivation in the wild-type background (Figure 3), indicating that the SOS response is poorly induced in the wild-type 
strain under the growth conditions used in our study. Since fast-growing colonies still emerged when the holD $\triangle r e c A$ conditional mutant was streaked onto agar plates in the absence of the inducer (Figure $4 \mathrm{~b}$ ), we compared the frequency of these variants between SOS response-proficient or -deficient HolD-depleted cells. The holD $\triangle r e c A$ conditional mutant showed an 80-fold reduction in the frequency of fast-growing colonies with respect to its RecA-proficient parental strain (Figure 4c). This implies that RecA is required for most of the genetic and/or adaptive mechanisms involved in the emergence of these variants, even if they can arise with a relevant frequency $\left(>10^{-6}\right)$ also in a RecA-independent manner.
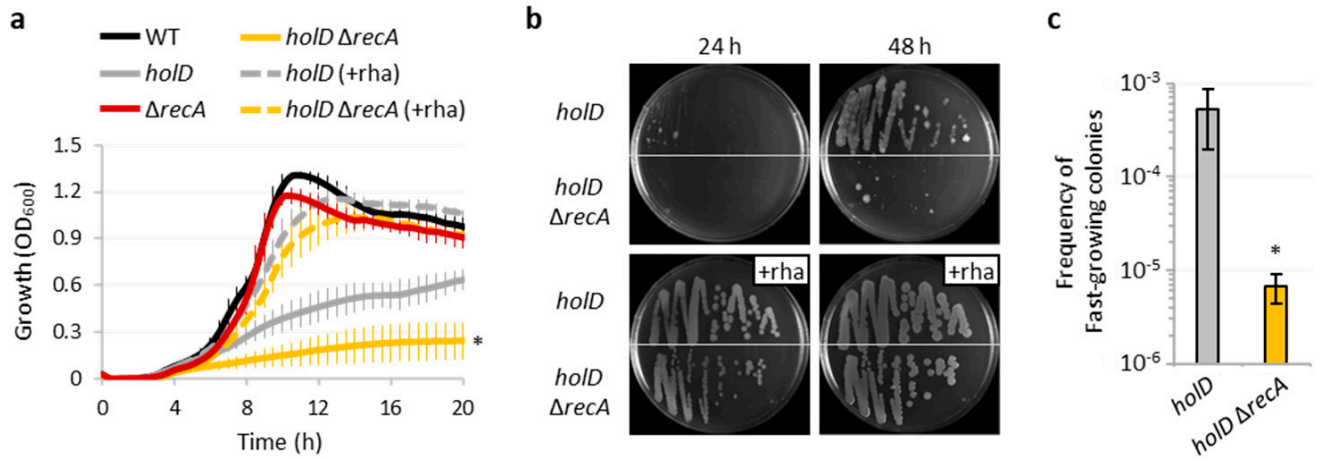

Figure 4. RecA is crucial for the residual growth of HolD-depleted P. aeruginosa cells. (a) Growth curves of the P. aeruginosa wild-type (WT) strain PAO1, the holD conditional mutant (holD), the $\triangle \operatorname{rec} A$ mutant, and the holD $\triangle \operatorname{rec} A$ conditional mutant at $37^{\circ} \mathrm{C}$ in $\mathrm{MH}$ supplemented or not with $0.01 \%$ rhamnose (+rha). (b) Growth of PAO1, holD, $\Delta r e c A$, and holD $\Delta r e c A$ strains on $\mathrm{MH}$ agar plates supplemented or not with rhamnose after 24 and $48 \mathrm{~h}$ of incubation at $37^{\circ} \mathrm{C}$. (c) Frequency of fast-growing colonies obtained on $\mathrm{MH}$ agar plates without rhamnose for the holD and holD $\triangle \mathrm{rec} A$ conditional mutants. Data are the mean $( \pm \mathrm{SD})$ of at least three independent assays. The asterisks indicate a statistically significant difference $(p<0.05)$ between the holD and holD $\triangle \operatorname{rec} A$ conditional mutants. The images in panel $(\mathbf{b})$ are representative of several experiments giving similar results.

\subsection{Specialized DNA Polymerases Marginally Affect the Viability of HolD-Depleted P. aeruginosa Cells}

The induction of the SOS response and the importance of RecA for growth and emergence of fast-growing variants upon HolD depletion support the hypothesis that specialized DNA polymerases could be involved in the viability of HolD-depleted P. aeruginosa cells. The three specialized DNA polymerases of E. coli, Pol II (PolB), and the error-prone enzymes Pol IV (DinB) and Pol V (UmuBC), are all induced by the SOS response [50]. P. aeruginosa also has three specialized DNA polymerases, namely PolB, DinB and ImuBC, a functional analog of Pol V [51], although $u m u B C$ orthologues have been recently identified in few clinical isolates [52]. While the operon that encodes ImuBC definitely belongs to the SOS regulon $[47,53,54]$, as confirmed in this work (Figure 3), the role of the SOS response in the control of $p o l B$ and $\operatorname{din} B$ gene expression in $P$. aeruginosa is less clear, with inconsistent results obtained in different studies $[47,55]$. Thus, we first analyzed by qRT-PCR whether these genes were induced in HolD-depleted cells in the presence and in the absence of a functional SOS response. The genes polA and polC, encoding the catalytic subunits of the replicative enzymes Pol I and Pol III, respectively, were included in the analysis as controls. No increase in the mRNA levels of $\operatorname{din} B$ and polC was observed in HolD-depleted $P$. aeruginosa cells, irrespective of the presence or the absence of RecA (Figure 3). In contrast, a significant downregulation of $p o l B$ and upregulation of $p o l A$ were observed in HolD-depleted cells, in a RecA-independent manner (Figure 3).

To verify whether any of the specialized polymerases contributes to the growth of cells lacking HolD, we generated holD and holD $\triangle \mathrm{rec} A$ conditional mutants also deleted in $p o l B, \operatorname{din} B$ or $i m u C$. The lack of $p o l B, \operatorname{din} B$ or $i m u C$ did not impair the growth of the holD conditional mutant and did not rescue the growth of the holD $\triangle r e c A$ conditional mutant under non-inducing conditions (Figure 5a,b), implying that the residual growth of 
HolD-depleted cells is not dependent on the presence of any specialized polymerase. As expected, the lack of specialized polymerases did not inhibit the growth of HolD-proficient wild-type and $\Delta r e c A$ cells, either (Figure S3). Additionally, the frequency of fast-growing variants obtained for the holD conditional mutants deficient in specialized polymerases was comparable to that of the corresponding parental strains (Figure $5 c$ ), indicating that the activity of error-prone polymerases is not the main mechanism that accounts for the emergence of these fast-growing variants.

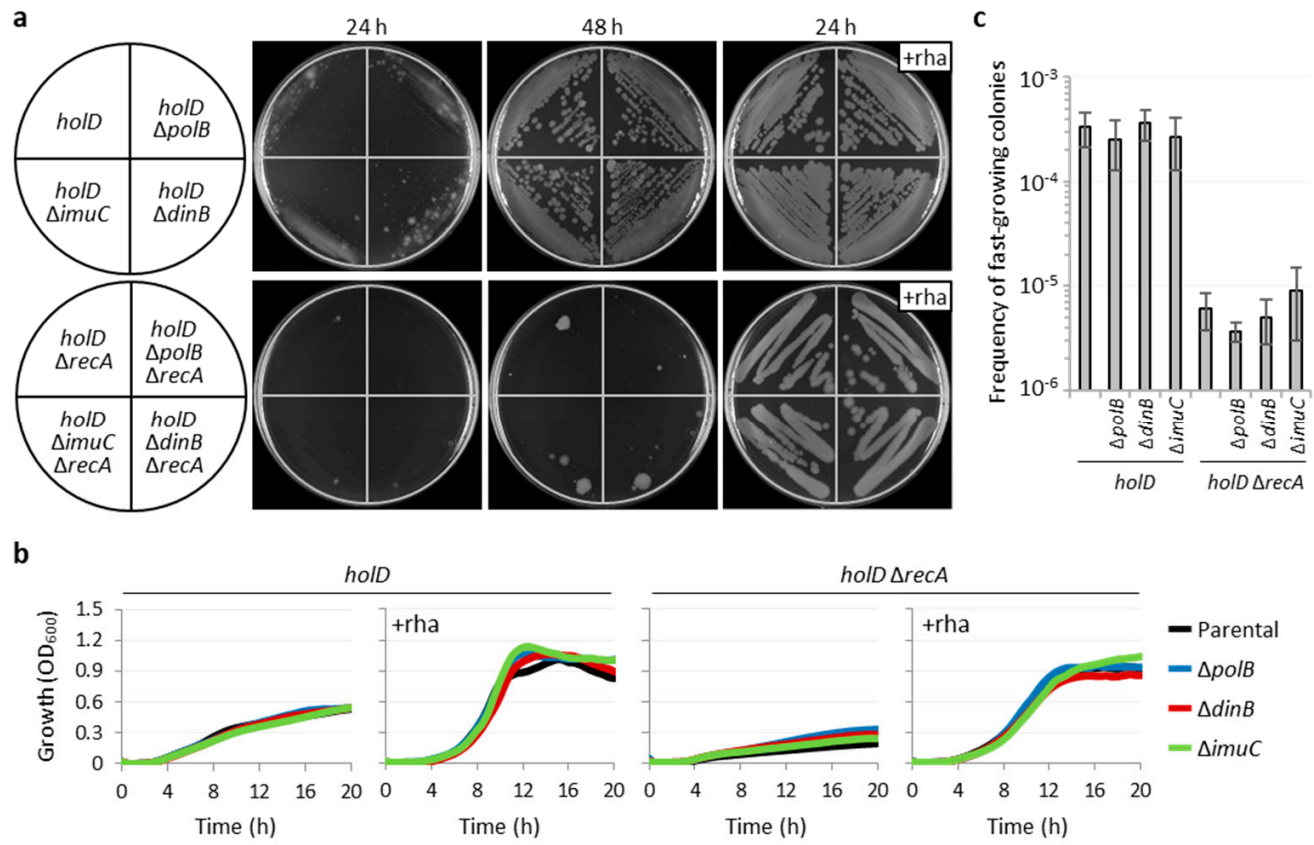

Figure 5. Specialized DNA polymerases do not account for residual growth and emergence of fastgrowing variants in the holD conditional mutant. (a) Growth of the P. aeruginosa holD conditional mutant (holD), the holD $\triangle r e c A$ conditional mutant and their cognate $p o l B$, $\operatorname{din} B$ or imuC deletion mutants on $\mathrm{MH}$ agar plates after 24 and $48 \mathrm{~h}$ of incubation at $37^{\circ} \mathrm{C}$. Images are representative of three independent assays. (b) Growth curves of the same strains described in panel (a) in $\mathrm{MH}$ at $37^{\circ} \mathrm{C}$. Data are the mean of three independent assays. When indicated, liquid and solid media were supplemented with $0.01 \%$ rhamnose (+rha). (c) Frequency of fast-growing colonies obtained on MH agar plates without rhamnose for the same strains described in panels $(\mathbf{a}, \mathbf{b})$. Data are the mean $( \pm S D)$ of five independent assays.

Several attempts to delete the polA gene were unsuccessful in all of our genetic backgrounds, suggesting that PolA deficiency strongly affects $P$. aeruginosa growth and/or cell viability. While this would be reasonable considering the involvement of PolA in removing RNA primers and filling the resulting gaps during replication [56], our inability to generate $\triangle$ polA mutants in P. aeruginosa is in contrast with the observation that viable knock-out mutants in polA have been obtained in random transposon mutagenesis studies [20-23], implying that this gene could be dispensable in P. aeruginosa. While the relevance of PolA in $P$. aeruginosa deserves further investigation, we can reasonably rule out that this DNA polymerase is responsible for the RecA-dependent residual growth of HolD-depleted cells, as it was found to be induced upon HolD depletion in both RecA-proficient and -deficient cells (Figure 3), although only the former showed relevant growth in the absence of rhamnose (Figure 4).

To further investigate the correlation between PolA activity and residual growth of HolD-depleted cells, the PolA enzyme was overexpressed from an IPTG-inducible plasmid (pMEpolA), and the growth of HolD-depleted cells was then monitored. As a control, the specialized DNA polymerases PolB, DinB and ImuBC were also individually overexpressed from the same plasmid vector. Except for pMEimuBC, the overexpression of all 
DNA polymerases inhibited the growth of HolD-depleted cells with respect to the empty plasmid controls, and none of them rescued the growth of HolD-depleted RecA-deficient cells (Figure S4). The inhibitory effect of polymerase-expressing constructs was also observed in HolD-depleted cells cultured without IPTG (Figure S4), plausibly because of leaky gene expression from the pME6032 plasmid in the absence of the inducer [57]. This effect appears to be dependent on HolD depletion, as the overexpression of the DNA polymerases marginally affected the growth of wild-type and $\Delta r e c A$ cells (Figure S4). Besides highlighting that HolD-deficient $P$. aeruginosa cells are highly sensitive to an unbalanced expression of specialized DNA polymerases, this experiment and, in particular, the results obtained with the pMEpolA construct corroborate that the observed induction of $\mathrm{polA}$ upon HolD depletion (Figure 3) likely does not account for the residual growth of HolD-depleted P. aeruginosa cells.

\subsection{Homologous Recombination Is Essential for HolD-Depleted P. aeruginosa Cells}

In addition to its role in triggering the SOS response, RecA is also crucial for homologous recombination. Indeed, RecA forms nucleoprotein filaments with ssDNA and is responsible for the invasion and scanning of dsDNA to recognize homologous sequences [58]. While homologous recombination has originally been investigated for its importance during horizontal gene transfer, it is now clear that the main function of this process is to support chromosome replication by repairing double-strand breaks and restarting stalled replication forks originating from DNA lesions and/or defects in the replisome activity [59,60].

To verify whether homologous recombination, rather than the activation of the SOS response, is required to sustain the growth of P. aeruginosa with a poorly functional HolDdeficient Pol III enzyme, we deleted the entire ruvCAB operon in the holD conditional mutant and in the wild-type strain. This operon encodes for three enzymes (RuvABC, also known as the resolvasome) that catalyze the resolution of Holliday junctions, i.e., the last step of homologous recombination, without being directly involved in the activation of the SOS response [61,62]. The holD $\triangle r u v C A B$ conditional mutant showed a growth phenotype reminiscent of the holD $\triangle r e c A$ conditional mutant, although the defects were somehow more exacerbated. Indeed, the growth was basically abrogated in the absence of rhamnose, and the frequency of fast-growing cell variants was further reduced with respect to the holD $\triangle r e c A$ mutant (Figure 6). It is interesting to note that $r u v C A B$ deletion in the wild-type background only caused a moderate defect in growth at the onset of the stationary phase (Figure 6a), in line with what was previously observed for the $\triangle \operatorname{rec} A$ mutant (Figure 4a). This suggests that neither replication fork reversal nor recombinational DNA repair are required for normal replication under the conditions used in our study or that alternative pathway(s) may compensate for the lack of RuvABC in HolD-proficient P. aeruginosa cells. In contrast, the growth of the holD conditional mutant deficient in Ruv proteins was also significantly impaired under holD-inducing conditions (Figure 6a). A less evident growth defect in the presence of rhamnose was observed for the holD $\triangle$ rec $A$ and, to a lesser extent, the holD conditional mutant (Figures 2a and 4a). Overall, these data suggest that replication might slightly be hampered when holD is induced in a rhamnosedependent non-physiological manner, and that this could result in a higher frequency of replication fork stalling. This would also explain why replication and growth are more closely dependent on homologous recombination proteins in holD conditional mutants, as compared to the wild-type strain. 


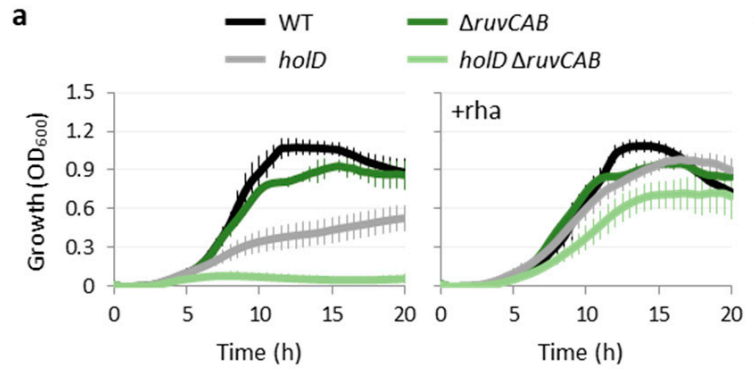

b

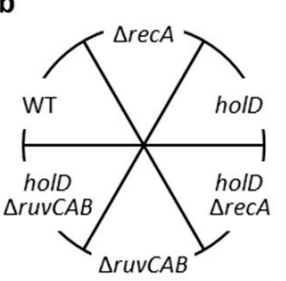

$24 \mathrm{~h}$

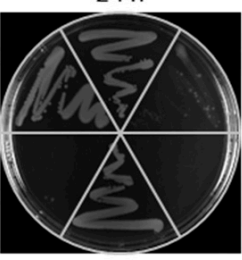

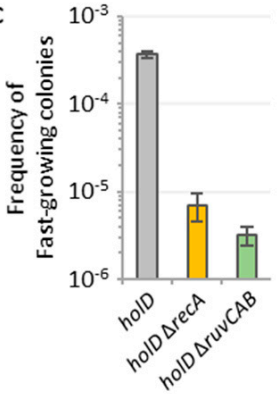

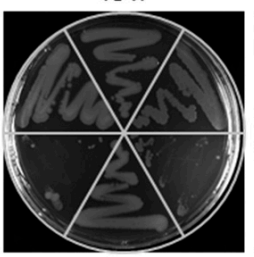

$24 \mathrm{~h}$

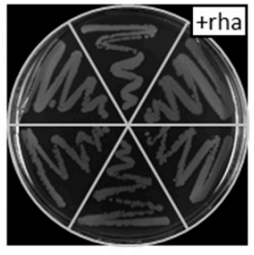

Figure 6. Homologous recombination is responsible for the residual growth of HolD-depleted P. aeruginosa cells. (a) Growth curves of the P. aeruginosa wild-type (WT) strain PAO1, the holD conditional mutant $(h o l D)$, and the cognate $\operatorname{rec} A$ and $\operatorname{ruv} \mathrm{CAB}$ deletion mutants in $\mathrm{MH}$ at $37^{\circ} \mathrm{C}$. Data are the mean of three independent assays. (b) Growth on $\mathrm{MH}$ agar plates of the same strains described in panel (a) after 24 and $48 \mathrm{~h}$ of incubation at $37^{\circ} \mathrm{C}$. Images are representative of several independent experiments. When indicated, liquid and solid media were supplemented with $0.01 \%$ rhamnose (+rha). (c) Frequency of fast-growing colonies obtained on MH agar plates without rhamnose for the same strains described in panels $(\mathbf{a}, \mathbf{b})$. Data are the mean $( \pm \mathrm{SD})$ of five independent assays.

\section{Discussion}

Most of the information available about DNA replication in bacteria and the functional properties of Pol III, the main replicative polymerase involved in this process, derives from studies performed in E. coli. This work originated from the observation that the clamp loader subunit $\psi$ of Pol III, which was proposed to be dispensable for E. coli growth and, thus, for Pol III activity in E. coli cells [15-17], appears to belong to the class of strictly essential genes in P. aeruginosa [20-25].

The in vitro biochemical characterization of the P. aeruginosa $\psi$ subunit (HolD) highlighted important differences with respect to its E. coli counterpart, such as larger size, ability to directly bind ssDNA, and essentiality for efficient clamp loader activity under physiological salt concentrations $[13,14]$. Nevertheless, here we demonstrate that the phenotypes of $P$. aeruginosa cells depleted of HolD mirror those of E. coli holD mutants. Indeed, as previously observed in E. coli $[16,17,19]$, HolD-depleted P. aeruginosa cells showed strongly reduced growth, constitutive activation of the SOS response, and frequent emergence of putative suppressor mutants (Figures 2-4). In addition, we found that HolD-depleted $P$. aeruginosa cells appear elongated with mislocalization of the $\mathrm{Z}$ ring (Figure 2), consistent with the intimate link between chromosome replication and cell division $[37,40,41]$. These features are suggestive of a defective replisome activity, which is generally associated with an increased frequency of stalled replication forks [16,44]. Accordingly, we observed that deletion of genes required for homologous recombination (rec $A$ or ruvCAB) abolishes the residual growth of HolD-depleted P. aeruginosa cells (Figures 4 and 6), indicating that recombination-mediated reactivation of arrested replication forks [63] plays a crucial role in fork restarting in P. aeruginosa.

RecA is a dual-function protein that, besides its role in homologous recombination, is also responsible for the activation of the SOS response, a regulatory circuit activated by DNA damages or replication perturbations that induces the expression of DNA repair systems and specialized error-prone DNA polymerases (also known as translesion DNA polymerases), that can bypass DNA lesions and promote replication of damaged 
DNA $[45,46,64]$. In E. coli, the SOS response contributes to the phenotypes of holD mutants, as it has been shown that inactivation of either the SOS-induced DNA polymerases PolB (Pol II) or DinB largely restores the growth of HolD-deficient cells [17]. This suggests that the interference of specialized DNA polymerases with a poorly functional $\psi$-deficient replicase is the main cause of growth defects in E. coli holD mutants, in line with the notion that the different DNA polymerases can compete for the $\beta$ clamp [65]. In contrast, we did not find a similar contribution of specialized DNA polymerases to the essentiality of HolD in P. aeruginosa. In fact, deletion of each specialized DNA polymerase of P. aeruginosa (PolB, DinB or ImuBC) did not rescue the growth of HolD-depleted cells, both in the presence or in the absence of a functional homologous recombination pathway (Figure 5). However, we observed a marked sensitivity of $P$. aeruginosa cells to the overexpression of PolB and DinB, but not ImuBC, in the absence of HolD (Figure S4), suggesting that also the replicase of $P$. aeruginosa is extremely sensitive to these two DNA polymerases when the clamp loader lacks the $\psi$ subunit. Notably, our qRT-PCR analysis showed that polB and $\operatorname{din} B$ are not induced by the SOS response in P. aeruginosa (Figure 3), in line with previous transcriptomics data [47]. So, the different effect of $p o l B$ or $\operatorname{din} B$ gene inactivation on the growth of HolD-depleted cells between P. aeruginosa and E. coli is likely due to the different regulatory circuits that trigger the expression of these polymerases in the two bacteria.

Finally, we observed a high frequency of putative suppressor mutants in P. aeruginosa when HolD is not expressed (Figures 2 and 4-6). This was also reported for E. coli cells with defective clamp loader complex $[17,19,66]$. Interestingly, the emergence of these suppressor mutants in HolD-depleted P. aeruginosa cells does not depend on the errorprone DNA polymerases DinB and ImuBC (Figure 5) but is significantly reduced when the homologous recombination pathway is inactivated (Figures 4 and 6). Previous works have shown that the genetic diversity observed in P. aeruginosa cells growing as biofilm largely derives from the mutagenic repair of dsDNA breaks (DSBs), and that it is abrogated in transposon insertion mutants deficient in RecA or Ruv proteins $[67,68]$. By analogy, it could be reasoned that this process promotes the emergence of putative suppressor mutants observed in HolD-depleted P. aeruginosa cultures. However, these suppressors were still detected at a relatively high frequency $\left(>10^{-6}\right)$ even upon deletion of recombination genes recA or $r u v C A B$. In E. coli, where some of the suppressor mutations allowing growth of replicase-defective mutants have been characterized, these mutations can affect a variety of physiological functions besides those directly related to replication, such as ion transport, transcription, and cell metabolism $[19,66,69]$. If this is true for other bacteria as well, such a high number of possible targets could justify the high frequency of suppressor mutants observed in our P. aeruginosa holD conditional mutant. Further work is required to verify this hypothesis and to explore the genetic determinants that can rescue the growth of $P$. aeruginosa cells with a defective clamp loader complex. Considering the interest in bacterial replication as a potential target for drug discovery and rational design [11], this information would be useful to evaluate the suitability of clamp loader inhibitors and/or to propose alternative strategies to interfere with DNA replication in bacterial pathogens. Reference [70] is cited in the supplementary materials.

Supplementary Materials: The following supporting information can be downloaded at https: / / www.mdpi.com/article/10.3390/microorganisms10020423/s1, Table S1, Bacterial strains and plasmids used in this study; Table S2, Primers used in this study; Figure S1, holD genetic locus and DNA sequence in P. aeruginosa PAO1; Figure S2, Growth and confocal microscopy analysis of $P$. aeruginosa PAO1 expressing the fusion protein FtsZ-GFP; Figure S3, Growth of $P$. aeruginosa PAO1, the $\triangle r e c A$ mutant and their cognate $p o l B, \operatorname{din} B$ or imuC deletion mutants; Figure S4, Effect of PolA, PolB, DinB or ImuBC overexpression on the growth of HolD-deficient and -proficient P. aeruginosa cells.

Author Contributions: Conceptualization, M.C.S., A.L.S. and F.I.; methodology, M.C.S., A.L.S., J.M. and M.L.; validation, all authors; investigation, M.C.S., A.L.S., J.M. and M.L.; resources, L.L., G.R., P.V. and F.I.; data curation, M.C.S., A.L.S., M.L. and F.I.; writing-original draft preparation, M.C.S. and F.I.; writing—review and editing, all authors; visualization, all authors; supervision, F.I.; 
project administration, F.I.; funding acquisition, P.V. and F.I. All authors have read and agreed to the published version of the manuscript.

Funding: This research was funded by PRIN 2017 (protocol 20177J5Y3P), PRIN 2020 (protocol 20208LLXEJ) and the Excellence Departments (Art. 1, commi 314-337 Legge 232/2016) grants from the Italian Ministry of Education, University and Research (MIUR, Italy), and by the Regione Lazio (Gruppi di Ricerca 2020, POR A0375E0026).

Institutional Review Board Statement: Not applicable.

Informed Consent Statement: Not applicable.

Data Availability Statement: Not applicable.

Acknowledgments: We are grateful to Giulia Radocchia for technical assistance in the construction of pMEftsZ-GFP during the preparation of her bachelor thesis.

Conflicts of Interest: The authors declare no conflict of interest. The funders had no role in the design of the study; in the collection, analyses, or interpretation of data; in the writing of the manuscript, or in the decision to publish the results.

\section{References}

1. Pomerantz, R.T.; O'Donnell, M. Replisome mechanics: Insights into a twin DNA polymerase machine. Trends Microbiol. 2007, 15, 156-164. [CrossRef] [PubMed]

2. Langston, L.D.; Indiani, C.; O'Donnell, M. Whither the replisome: Emerging perspectives on the dynamic nature of the DNA replication machinery. Cell Cycle 2009, 8, 2686-2691. [CrossRef] [PubMed]

3. Oakley, A.J. A structural view of bacterial DNA replication. Protein Sci. 2019, 28, 990-1004. [CrossRef] [PubMed]

4. O'Donnell, M. Replisome architecture and dynamics in Escherichia coli. J. Biol. Chem. 2006, 281, 10653-10656. [CrossRef]

5. McHenry, C.S. Bacterial replicases and related polymerases. Curr. Opin. Chem. Biol. 2011, 15, 587-594. [CrossRef] [PubMed]

6. Dietrich, M.; Pedró, L.; García, J.; Pons, M.; Hüttener, M.; Paytubi, S.; Madrid, C.; Juárez, A. Evidence for moonlighting functions of the $\theta$ subunit of Escherichia coli DNA polymerase III. J. Bacteriol. 2014, 196, 1102-1112. [CrossRef]

7. Kelch, B.A.; Makino, D.L.; O'Donnell, M.; Kuriyan, J. Clamp loader ATPases and the evolution of DNA replication machinery. BMC Biol. 2012, 10, 34. [CrossRef]

8. Kelch, B.A. Review: The lord of the rings: Structure and mechanism of the sliding clamp loader. Biopolymers 2016, 105, 532-546. [CrossRef]

9. Yuzhakov, A.; Turner, J.; O’Donnell, M. Replisome assembly reveals the basis for asymmetric function in leading and lagging strand replication. Cell 1996, 86, 877-886. [CrossRef]

10. Schaeffer, P.M.; Headlam, M.J.; Dixon, N.E. Protein-protein interactions in the eubacterial replisome. IUBMB Life 2005, 57, 5-12. [CrossRef]

11. Robinson, A.; Causer, R.J.; Dixon, N.E. Architecture and conservation of the bacterial DNA replication machinery, an underexploited drug target. Curr. Drug Targets 2012, 13, 352-372. [CrossRef]

12. Jarvis, T.C.; Beaudry, A.A.; Bullard, J.M.; Janjic, N.; McHenry, C.S. Reconstitution of a minimal DNA replicase from Pseudomonas aeruginosa and stimulation by non-cognate auxiliary factors. J. Biol. Chem. 2005, 280, 7890-7900. [CrossRef] [PubMed]

13. Jarvis, T.C.; Beaudry, A.A.; Bullard, J.M.; Ochsner, U.; Dallmann, H.G.; McHenry, C.S. Discovery and characterization of the cryptic psi subunit of the pseudomonad DNA replicase. J. Biol. Chem. 2005, 280, 40465-40473. [CrossRef]

14. El Houry Mignan, S.; Witte, G.; Naue, N.; Curth, U. Characterization of the $\chi \psi$ subcomplex of Pseudomonas aeruginosa DNA polymerase III. BMC Mol. Biol. 2011, 12, 43. [CrossRef]

15. Baba, T.; Ara, T.; Hasegawa, M.; Takai, Y.; Okumura, Y.; Baba, M.; Datsenko, K.A.; Tomita, M.; Wanner, B.L.; Mori, H. Construction of Escherichia coli K-12 in-frame, single-gene knockout mutants: The Keio collection. Mol. Syst. Biol. 2006, 2, 2006.0008. [CrossRef] [PubMed]

16. Flores, M.J.; Bierne, H.; Ehrlich, S.D.; Michel, B. Impairment of lagging strand synthesis triggers the formation of a RuvABC substrate at replication forks. EMBO J. 2001, 20, 619-629. [CrossRef]

17. Viguera, E.; Petranovic, M.; Zahradka, D.; Germain, K.; Ehrlich, D.S.; Michel, B. Lethality of bypass polymerases in Escherichia coli cells with a defective clamp loader complex of DNA polymerase III. Mol. Microbiol. 2003, 50, 193-204. [CrossRef]

18. Goodall, E.C.; Robinson, A.; Johnston, I.G.; Jabbari, S.; Turner, K.A.; Cunningham, A.F.; Lund, P.A.; Cole, J.A.; Henderson, I.R. The Essential Genome of Escherichia coli K-12. mBio 2018, 9, e02096-17. [CrossRef]

19. Durand, A.; Sinha, A.K.; Dard-Dascot, C.; Michel, B. Mutations Affecting Potassium Import Restore the Viability of the Escherichia coli DNA Polymerase III holD Mutant. PLoS Genet. 2016, 12, e1006114. [CrossRef] [PubMed]

20. Jacobs, M.A.; Alwood, A.; Thaipisuttikul, I.; Spencer, D.; Haugen, E.; Ernst, S.; Will, O.; Kaul, R.; Raymond, C.; Levy, R.; et al. Comprehensive transposon mutant library of Pseudomonas aeruginosa. Proc. Natl. Acad. Sci. USA 2003, 100, 14339-14344. [CrossRef] [PubMed] 
21. Liberati, N.T.; Urbach, J.M.; Miyata, S.; Lee, D.G.; Drenkard, E.; Wu, G.; Villanueva, J.; Wei, T.; Ausubel, F.M. An ordered, nonredundant library of Pseudomonas aeruginosa strain PA14 transposon insertion mutants. Proc. Natl. Acad. Sci. USA 2006, 103, 2833-2838. [CrossRef] [PubMed]

22. Lee, S.A.; Gallagher, L.A.; Thongdee, M.; Staudinger, B.J.; Lippman, S.; Singh, P.K.; Manoil, C. General and condition-specific essential functions of Pseudomonas aeruginosa. Proc. Natl. Acad. Sci. USA 2015, 112, 5189-5194. [CrossRef] [PubMed]

23. Turner, K.H.; Wessel, A.K.; Palmer, G.C.; Murray, J.L.; Whiteley, M. Essential genome of Pseudomonas aeruginosa in cystic fibrosis sputum. Proc. Natl. Acad. Sci. USA 2015, 112, 4110-4115. [CrossRef] [PubMed]

24. Skurnik, D.; Roux, D.; Aschard, H.; Cattoir, V.; Yoder-Himes, D.; Lory, S.; Pier, G.B. A comprehensive analysis of in vitro and in vivo genetic fitness of Pseudomonas aeruginosa using high-throughput sequencing of transposon libraries. PLoS Pathog. 2013, 9, e1003582. [CrossRef] [PubMed]

25. Poulsen, B.E.; Yang, R.; Clatworthy, A.E.; White, T.; Osmulski, S.J.; Li, L.; Penaranda, C.; Lander, E.S.; Shoresh, N.; Hung, D.T. Defining the core essential genome of Pseudomonas aeruginosa. Proc. Natl. Acad. Sci. USA 2019, 116, 10072-10080. [CrossRef] [PubMed]

26. Sambrook, J.; Fritsch, E.F.; Maniatis, T. Molecular Cloning: A Laboratory Manual, 2nd ed.; Cold Spring Harbor Laboratory: New York, NY, USA, 1989.

27. Meisner, J.; Goldberg, J.B. The Escherichia coli rhaSR-PrhaBAD Inducible Promoter System Allows Tightly Controlled Gene Expression over a Wide Range in Pseudomonas aeruginosa. Appl. Environ. Microbiol. 2016, 82, 6715-6727. [CrossRef]

28. Milton, D.L.; O'Toole, R.; Horstedt, P.; Wolf-Watz, H. Flagellin A is essential for the virulence of Vibrio anguillarum. J. Bacteriol. 1996, 178, 1310-1319. [CrossRef]

29. Scala, R.; Di Matteo, A.; Coluccia, A.; Lo Sciuto, A.; Federici, L.; Travaglini-Allocatelli, C.; Visca, P.; Silvestri, R.; Imperi, F Mutational analysis of the essential lipopolysaccharide-transport protein LptH of Pseudomonas aeruginosa to uncover critical oligomerization sites. Sci. Rep. 2020, 10, 11276. [CrossRef]

30. Hoang, T.T.; Karkhoff-Schweizer, R.R.; Kutchma, A.J.; Schweizer, H.P. A broad-host-range Flp-FRT recombination system for site-specific excision of chromosomally-located DNA sequences: Application for isolation of unmarked Pseudomonas aeruginosa mutants. Gene 1998, 212, 77-86. [CrossRef]

31. Heeb, S.; Blumer, C.; Haas, D. Regulatory RNA as mediator in GacA/RsmA-dependent global control of exoproduct formation in Pseudomonas fluorescens CHA0. J. Bacteriol. 2002, 184, 1046-1056. [CrossRef]

32. Lo Sciuto, A.; Spinnato, M.C.; Pasqua, M.; Imperi, F. Generation of stable and unmarked conditional mutants in Pseudomonas aeruginosa. Methods Mol. Biol. 2022, in press.

33. Hoang, T.T.; Kutchma, A.J.; Becher, A.; Schweizer, H.P. Integration-proficient plasmids for Pseudomonas aeruginosa: Site-specific integration and use for engineering of reporter and expression strains. Plasmid 2000, 43, 59-72. [CrossRef] [PubMed]

34. Lo Sciuto, A.; Fernández-Piñar, R.; Bertuccini, L.; Iosi, F.; Superti, F.; Imperi, F. The periplasmic protein TolB as a potential drug target in Pseudomonas aeruginosa. PLoS ONE 2014, 9, e103784. [CrossRef] [PubMed]

35. Livak, K.J.; Schmittgen, T.D. Analysis of relative gene expression data using real-time quantitative PCR and the 2(-Delta Delta C(T)) Method. Methods 2001, 25, 402-408. [CrossRef]

36. Kaimer, C.; Schenk, K.; Graumann, P.L. Two DNA Translocases Synergistically Affect Chromosome Dimer Resolution in Bacillus Subtilis. J. Bacteriol. 2011, 193, 1334-1340. [CrossRef]

37. Kawakami, H.; Iwura, T.; Takata, M.; Sekimizu, K.; Hiraga, S.; Katayama, T. Arrest of cell division and nucleoid partition by genetic alterations in the sliding clamp of the replicase and in DnaA. Mol. Genet Genom. 2001, 266, 167-179. [CrossRef] [PubMed]

38. Strauss, B.; Kelly, K.; Dincman, T.; Ekiert, D.; Biesieda, T.; Song, R. Cell death in Escherichia coli dnaE(Ts) mutants incubated at a nonpermissive temperature is prevented by mutation in the cydA gene. J. Bacteriol. 2004, 186, 2147-2155. [CrossRef]

39. Strauss, B.; Kelly, K.; Ekiert, D. Cytochrome oxidase deficiency protects Escherichia coli from cell death but not from filamentation due to thymine deficiency or DNA polymerase inactivation. J. Bacteriol. 2005, 187, 2827-2835. [CrossRef]

40. Reyes-Lamothe, R.; Nicolas, E.; Sherratt, D.J. Chromosome replication and segregation in bacteria. Annu. Rev. Genet. 2012, 46, 121-143. [CrossRef]

41. Kleckner, N.E.; Chatzi, K.; White, M.A.; Fisher, J.K.; Stouf, M. Coordination of Growth, Chromosome Replication/Segregation, and Cell Division in, E. coli. Front. Microbiol. 2018, 9, 1469. [CrossRef]

42. Haeusser, D.P.; Margolin, W. Splitsville: Structural and functional insights into the dynamic bacterial Z ring. Nat. Rev. Microbiol. 2016, 14, 305-319. [CrossRef]

43. Barrows, J.M.; Goley, E.D. FtsZ dynamics in bacterial division: What, how, and why? Curr. Opin. Cell Biol. 2021, 68, 163-172. [CrossRef] [PubMed]

44. Grompone, G.; Seigneur, M.; Ehrlich, S.D.; Michel, B. Replication fork reversal in DNA polymerase III mutants of Escherichia coli: A role for the beta clamp. Mol. Microbiol. 2002, 44, 1331-1339. [CrossRef] [PubMed]

45. Henrikus, S.S.; van Oijen, A.M.; Robinson, A. Specialised DNA polymerases in Escherichia coli: Roles within multiple pathways. Curr. Genet. 2018, 64, 1189-1196. [CrossRef] [PubMed]

46. Revitt-Mills, S.A.; Robinson, A. Antibiotic-Induced Mutagenesis: Under the Microscope. Front. Microbiol. $2020,11,585175$. [CrossRef] [PubMed]

47. Cirz, R.T.; O'Neill, B.M.; Hammond, J.A.; Head, S.R.; Romesberg, F.E. Defining the Pseudomonas aeruginosa SOS response and its role in the global response to the antibiotic ciprofloxacin. J. Bacteriol. 2006, 188, 7101-7110. [CrossRef] [PubMed] 
48. Breidenstein, E.B.; Bains, M.; Hancock, R.E. Involvement of the lon protease in the SOS response triggered by ciprofloxacin in Pseudomonas aeruginosa PAO1. Antimicrob. Agents Chemother. 2012, 56, 2879-2887. [CrossRef]

49. Chen, F.; Chen, G.; Liu, Y.; Jin, Y.; Cheng, Z.; Liu, Y.; Yang, L.; Jin, S.; Wu, W. Pseudomonas aeruginosa Oligoribonuclease Contributes to Tolerance to Ciprofloxacin by Regulating Pyocin Biosynthesis. Antimicrob. Agents Chemother. 2017, 61, e02256-16. [CrossRef]

50. Napolitano, R.; Janel-Bintz, R.; Wagner, J.; Fuchs, R.P. All three SOS-inducible DNA polymerases (Pol, I.I.; Pol IV and Pol V) are involved in induced mutagenesis. EMBO J. 2000, 19, 6259-6265. [CrossRef]

51. Kivisaar, M. Mechanisms of stationary-phase mutagenesis in bacteria: Mutational processes in pseudomonads. FEMS Microbiol. Lett. 2010, 312, 1-14. [CrossRef]

52. Migliorini, L.B.; Brüggemann, H.; de Sales, R.O.; Koga, P.C.M.; de Souza, A.V.; Martino, M.D.V.; Galhardo, R.S.; Severino, P. Mutagenesis Induced by Sub-Lethal Doses of Ciprofloxacin: Genotypic and Phenotypic Differences Between the Pseudomonas aeruginosa Strain PA14 and Clinical Isolates. Front. Microbiol. 2019, 10, 1553. [CrossRef] [PubMed]

53. Abella, M.; Erill, I.; Jara, M.; Mazón, G.; Campoy, S.; Barbé, J. Widespread distribution of a lexA-regulated DNA damage-inducible multiple gene cassette in the Proteobacteria phylum. Mol Microbiol. 2004, 54, 212-222. [CrossRef] [PubMed]

54. Luján, A.M.; Moyano, A.J.; Martino, R.A.; Feliziani, S.; Urretavizcaya, M.; Smania, A.M. ImuB and ImuC contribute to UV-induced mutagenesis as part of the SOS regulon in Pseudomonas aeruginosa. Environ. Mol. Mutagen. 2019, 60, 594-601. [CrossRef]

55. Sanders, L.H.; Rockel, A.; Lu, H.; Wozniak, D.J.; Sutton, M.D. Role of Pseudomonas aeruginosa dinB-encoded DNA polymerase IV in mutagenesis. J. Bacteriol. 2006, 188, 8573-8585. [CrossRef]

56. Patel, P.H.; Suzuki, M.; Adman, E.; Shinkai, A.; Loeb, L.A. Prokaryotic DNA polymerase I: Evolution, structure, and “base flipping" mechanism for nucleotide selection. J. Mol. Biol. 2001, 308, 823-837. [CrossRef] [PubMed]

57. Cervoni, M.; Lo Sciuto, A.; Bianchini, C.; Mancone, C.; Imperi, F. Exogenous and Endogenous Phosphoethanolamine Transferases Differently Affect Colistin Resistance and Fitness in Pseudomonas aeruginosa. Front. Microbiol. 2021, 12, 778968. [CrossRef]

58. Del Val, E.; Nasser, W.; Abaibou, H.; Reverchon, S. RecA and DNA recombination: A review of molecular mechanisms. Biochem. Soc. Trans. 2019, 47, 1511-1531. [CrossRef]

59. Cox, M.M.; Goodman, M.F.; Kreuzer, K.N.; Sherratt, D.J.; Sandler, S.J.; Marians, K.J. The importance of repairing stalled replication forks. Nature 2000, 404, 37-41. [CrossRef]

60. Cox, M.M. Recombinational DNA repair of damaged replication forks in Escherichia coli: Questions. Annu. Rev. Genet. 2001, 35, 53-82. [CrossRef]

61. McKenzie, G.J.; Harris, R.S.; Lee, P.L.; Rosenberg, S.M. The SOS response regulates adaptive mutation. Proc. Natl. Acad. Sci. USA 2000, 97, 6646-6651. [CrossRef]

62. Dickman, M.J.; Ingleston, S.M.; Sedelnikova, S.E.; Rafferty, J.B.; Lloyd, R.G.; Grasby, J.A.; Hornby, D.P. The RuvABC resolvasome. Eur. J. Biochem. 2002, 269, 5492-5501. [CrossRef] [PubMed]

63. Michel, B.; Boubakri, H.; Baharoglu, Z.; LeMasson, M.; Lestini, R. Recombination proteins and rescue of arrested replication forks. DNA Repair 2007, 6, 967-980. [CrossRef] [PubMed]

64. Goodman, M.F.; Woodgate, R. Translesion DNA polymerases. Cold Spring Harb. Perspect. Biol. 2013, 5, a010363. [CrossRef] [PubMed]

65. Sutton, M.D. Coordinating DNA polymerase traffic during high and low fidelity synthesis. Biochim. Biophys. Acta 2010, 1804, 1167-1179. [CrossRef] [PubMed]

66. Cooper, D.L.; Harada, T.; Tamazi, S.; Ferrazzoli, A.E.; Lovett, S.T. The Role of Replication Clamp-Loader Protein HolC of Escherichia coli in Overcoming Replication/Transcription Conflicts. mBio 2021, 12, e00184-21. [CrossRef]

67. Boles, B.R.; Thoendel, M.; Singh, P.K. Self-generated diversity produces "insurance effects" in biofilm communities. Proc. Natl. Acad. Sci. USA 2004, 101, 16630-16635. [CrossRef]

68. Boles, B.R.; Singh, P.K. Endogenous oxidative stress produces diversity and adaptability in biofilm communities. Proc. Natl. Acad. Sci. USA 2008, 105, 12503-12508. [CrossRef]

69. Maciag, M.; Nowicki, D.; Janniere, L.; Szalewska-Pałasz, A.; Węgrzyn, G. Genetic response to metabolic fluctuations: Correlation between central carbon metabolism and DNA replication in Escherichia coli. Microb. Cell Fact. 2011, 10, 19. [CrossRef]

70. Simon, R.; Priefer, U.; Pühler, A. A Broad Host Range Mobilization System for In Vivo Genetic Engineering: Transposon Mutagenesis in Gram Negative Bacteria. Nat. Biotechnol. 1983, 1, 784-791. [CrossRef] 